\title{
Body size and weight change over adulthood and risk of breast cancer by menopausal and hormone receptor status: a pooled analysis of 20 prospective cohort studies
}

\author{
Piet A. van den Brandt ${ }^{1,2}$ - $\cdot$ Regina G. Ziegler ${ }^{3} \cdot$ Molin Wang ${ }^{4,5,6} \cdot$ Tao Hou $^{7} \cdot$ Ruifeng $\mathrm{Li}^{7} \cdot$ Hans-Olov Adami ${ }^{8,9}$. \\ Claudia Agnoli ${ }^{10}$. Leslie Bernstein ${ }^{11}$. Julie E. Buring ${ }^{4,12} \cdot$ Yu Chen ${ }^{13}$. Avonne E. Connor ${ }^{14}$. A. Heather Eliassen ${ }^{4,6}$. \\ Jeanine M. Genkinger ${ }^{15,16}$. Gretchen Gierach ${ }^{3}$. Graham G. Giles ${ }^{17,18,19}$. Gary G. Goodman ${ }^{20}$. Niclas Håkansson ${ }^{21}$. \\ Vittorio $\mathrm{Krogh}^{10}$. Loic Le Marchand ${ }^{22} \cdot$ I-Min Lee ${ }^{4,12} \cdot$ Linda M. Liao $^{3} \cdot$ M. Elena Martinez ${ }^{23,24}$. Anthony B. Miller ${ }^{25}$. \\ Roger L. Milne ${ }^{17,18,19} \cdot$ Marian L. Neuhouser ${ }^{20} \cdot$ Alpa V. Patel $^{26} \cdot$ Anna Prizment $^{27,28} \cdot$ Kim Robien $^{29}$. \\ Thomas E. Rohan ${ }^{30} \cdot$ Norie Sawada $^{31}$ - Leo J. Schouten ${ }^{1} \cdot$ Rashmi Sinha $^{3} \cdot$ Rachael Z. Stolzenberg-Solomon $^{3}$. \\ Lauren R. Teras ${ }^{26}$. Shoichiro Tsugane ${ }^{31}$. Kala Visvanathan ${ }^{14}$. Elisabete Weiderpass ${ }^{32} \cdot$ Kami K. White $^{22}$. \\ Walter C. Willett $^{4,6,7}$. Alicja Wolk ${ }^{21,33}$. Anne Zeleniuch-Jacquotte ${ }^{13}$. Stephanie A. Smith-Warner ${ }^{4,7}$
}

Received: 31 August 2020 / Accepted: 26 September 2020 / Published online: 30 October 2020

(c) The Author(s) 2020

\begin{abstract}
Associations between anthropometric factors and breast cancer (BC) risk have varied inconsistently by estrogen and/or progesterone receptor (ER/PR) status. Associations between prediagnostic anthropometric factors and risk of premenopausal and postmenopausal BC overall and ER/PR status subtypes were investigated in a pooled analysis of 20 prospective cohorts, including 36,297 BC cases among 1,061,915 women, using multivariable Cox regression analyses, controlling for reproductive factors, diet and other risk factors. We estimated dose-response relationships and tested for nonlinear associations using restricted cubic splines. Height showed positive, linear associations for premenopausal and postmenopausal BC risk (6-7\% RR increase per $5 \mathrm{~cm}$ increment), with stronger associations for receptor-positive subtypes. Body mass index (BMI) at cohort baseline was strongly inversely associated with premenopausal BC risk, and strongly positively — and nonlinearlyassociated with postmenopausal BC (especially among women who never used hormone replacement therapy). This was primarily observed for receptor-positive subtypes. Early adult BMI (at 18-20 years) showed inverse, linear associations for premenopausal and postmenopausal BC risk ( $21 \%$ and $11 \%$ RR decrease per $5 \mathrm{~kg} / \mathrm{m}^{2}$, respectively) with stronger associations for receptor-negative subtypes. Adult weight gain since 18-20 years was positively associated with postmenopausal $\mathrm{BC}$ risk, stronger for receptor-positive subtypes, and among women who were leaner in early adulthood. Women heavier in early adulthood generally had reduced premenopausal BC risk, independent of later weight gain. Positive associations between height, baseline (adult) BMI, adult weight gain and postmenopausal BC risk were substantially stronger for hormone receptor-positive versus negative subtypes. Premenopausal BC risk was positively associated with height, but inversely with baseline BMI and weight gain (mostly in receptor-positive subtypes). Inverse associations with early adult BMI seemed stronger in receptor-negative subtypes of premenopausal and postmenopausal BC.
\end{abstract}

Disclaimer: Where authors are identified as personnel of the International Agency for Research on Cancer/World Health Organization, the authors alone are responsible for the views expressed in this article and they do not necessarily represent the decisions, policy or views of the International Agency for Research on Cancer/World Health Organization.

Electronic supplementary material The online version of this article (https://doi.org/10.1007/s10654-020-00688-3) contains supplementary material, which is available to authorized users.

Extended author information available on the last page of the article 
Keywords Breast neoplasms $\cdot$ Body height $\cdot$ Body weight $\cdot$ Weight change $\cdot$ Estrogen receptor $\cdot$ Cohort studies

\section{Introduction}

Body height and weight have been consistently reported to be associated with breast cancer (BC) risk [1,2]. Height generally shows positive associations with both premenopausal and postmenopausal BC [1, 3-5]. Adult relative weight, as measured with body mass index (BMI) and weight gain since adolescence (18-20 years) are inversely associated with premenopausal $\mathrm{BC}$ risk, but positively associated with postmenopausal BC [1, 2, 6-11]. Early adult weight has been inversely, although inconsistently, related to both premenopausal and postmenopausal BC risk $[11,12]$.

Increasingly $\mathrm{BC}$ is recognized as a heterogeneous disease with distinct risk factors for tumor subtypes. Investigating how the anthropometry relationships with $\mathrm{BC}$ vary by steroid hormone receptor status may provide insight into $\mathrm{BC}$ etiology. For weight, the influence on postmenopausal BC risk seems related to hormonal pathways (steroids/estrogens) [13-17]. For postmenopausal BC, adult BMI may have a larger impact on risk of estrogen receptor positive $(\mathrm{ER}+) \mathrm{BC}$ than ER - tumors, because ER- tumors are less dependent on estrogen levels [14, 18]. However, studies of the associations between BMI and BC according to estrogen and/or progesterone receptor (PR) status $[8,17,19,20]$ have not been entirely consistent $[19,20]$. Associations with ER/PR subtypes have been investigated less extensively for early adult BMI, adult weight gain and height.

Meta-analyses [11, 20] of the associations between height, body weight, and weight change with $\mathrm{BC}$ risk indicate significant heterogeneity in the study-specific results and publication bias which hinders causal interpretation. Potential sources of heterogeneity include differences in how the exposures are (measured and) modeled and which covariates are included in the models. Meta-analyses of these exposures with $\mathrm{BC}$ subtypes defined by hormone receptor status are also limited by the relatively few studies that have reported on these associations. Furthermore, meta-analyses often assume linear associations (e.g., [2, 11]). These limitations of meta-analyses can be directly addressed in pooled analyses of individual data from multiple cohorts, because studies that have not previously published on the association can be included in the analysis thereby limiting publication bias. Furthermore, there is enhanced standardization of the exposures, outcomes, covariates, and modeling approach used. We therefore investigated detailed dose-response relationships between anthropometry and risk of BC by ER status, PR status, and joint ER/PR status in a large pooled analysis of the participant-level data from 20 prospective cohorts, including over 1 million women with more than 36,000 incident $\mathrm{BC}$ cases.

\section{Subjects and methods}

\section{Study population}

The Pooling Project of Prospective Studies of Diet and Cancer (DCPP) has been described previously [21]. For these analyses, we included 20 prospective cohorts [9, 10, 22-39] which met the following inclusion criteria: ascertainment of at least 25 incident cases of invasive ER- BC, prospective assessment of anthropometry and long-term dietary intake, and evaluation of the validity of the dietary assessment method or a closely related method. Each participating cohort, participating registries (as required), and the DCPP received approval from their respective institutional review boards.

\section{Ascertainment of $\mathrm{BC}$ cases}

Incident invasive BC cases were identified in the cohort studies through follow-up questionnaires and confirmed with subsequent medical record review $[9,32,36]$ or linkage with cancer registries [10, 22-24, 26, 27, 33, 35, 37, 40-42], both approaches [28, 31, 34, 39, 43], as well as through mortality registries [23, 26, 28, 32, 39, 43]. We used the steroid hormone receptor status data provided by each cohort to define BC subtypes. We classified cases with borderline ER/ PR status as positive for that receptor [44]. Approximately $28 \%$ of cases were missing ER/PR status, which were mostly from diagnoses prior to 2000 .

\section{Anthropometry and BC risk factors}

Prediagnostic anthropometry, menstrual and reproductive factors, medical history, family history of BC, dietary intake and physical activity were assessed by the cohorts at baseline with self-administered questionnaires. However, CARET, MCCS and ORDET measured height and weight. Weight at early adulthood (ages 18-20 years) was available for 15 cohorts (Table 1, including cohort abbreviations). BMI $\left(\mathrm{kg} / \mathrm{m}^{2}\right)$ was used as an indicator of adiposity in mid to later adulthood ('baseline BMI') and at ages 18-20 years ('early adult BMI'). Adult weight change ( $\mathrm{kg}$ ) was defined as the difference between cohort baseline weight and early adult weight. 


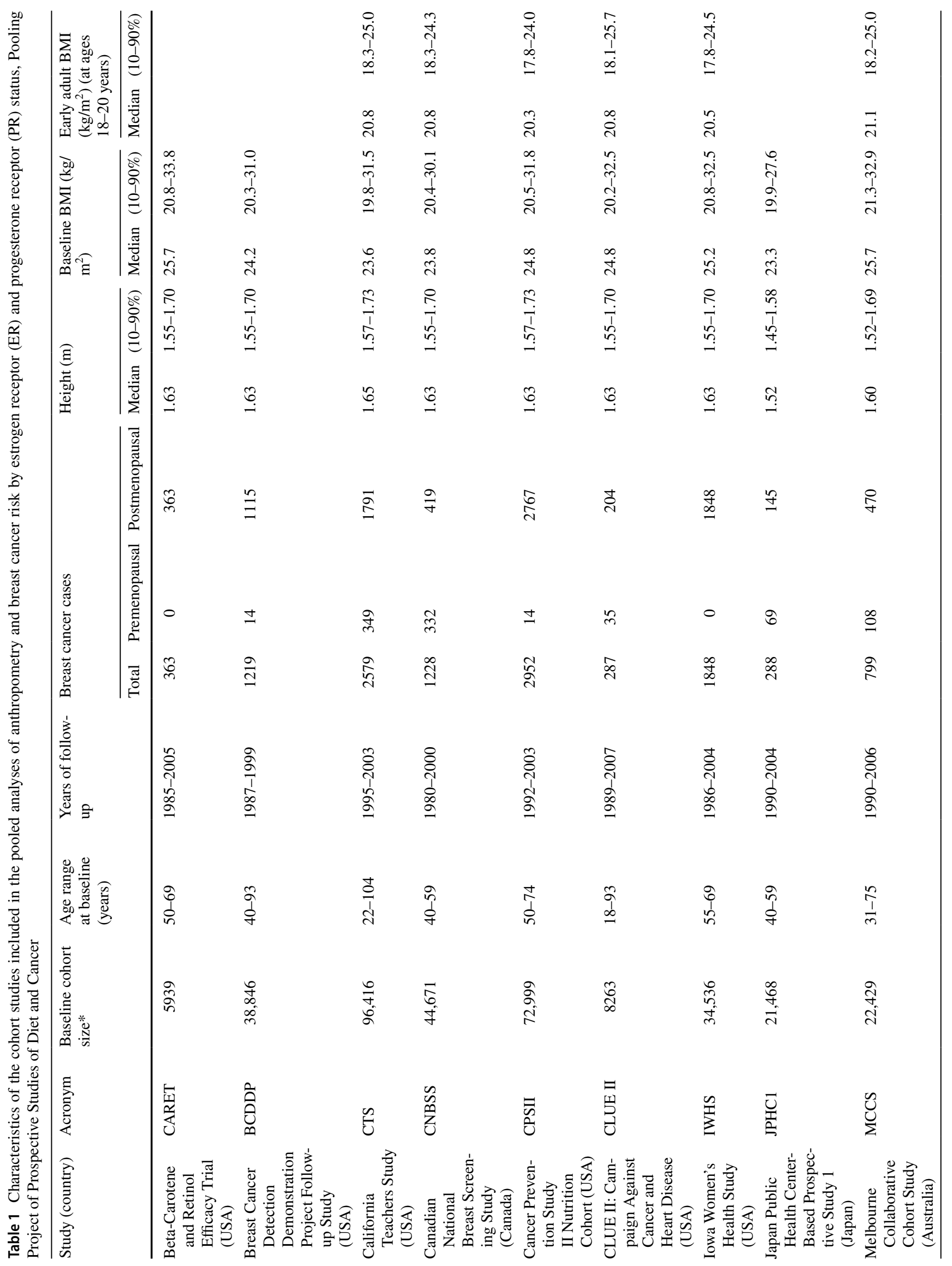




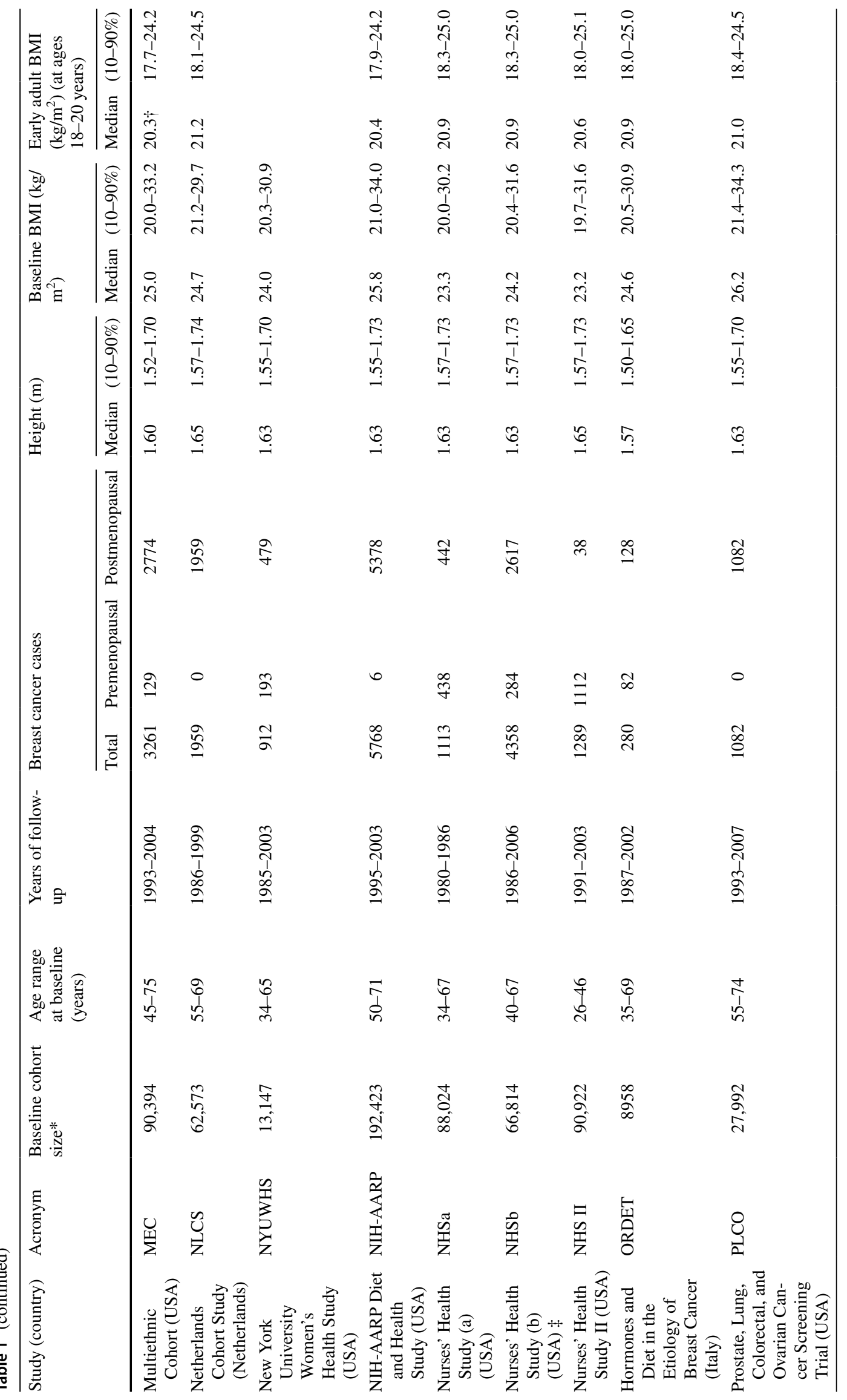




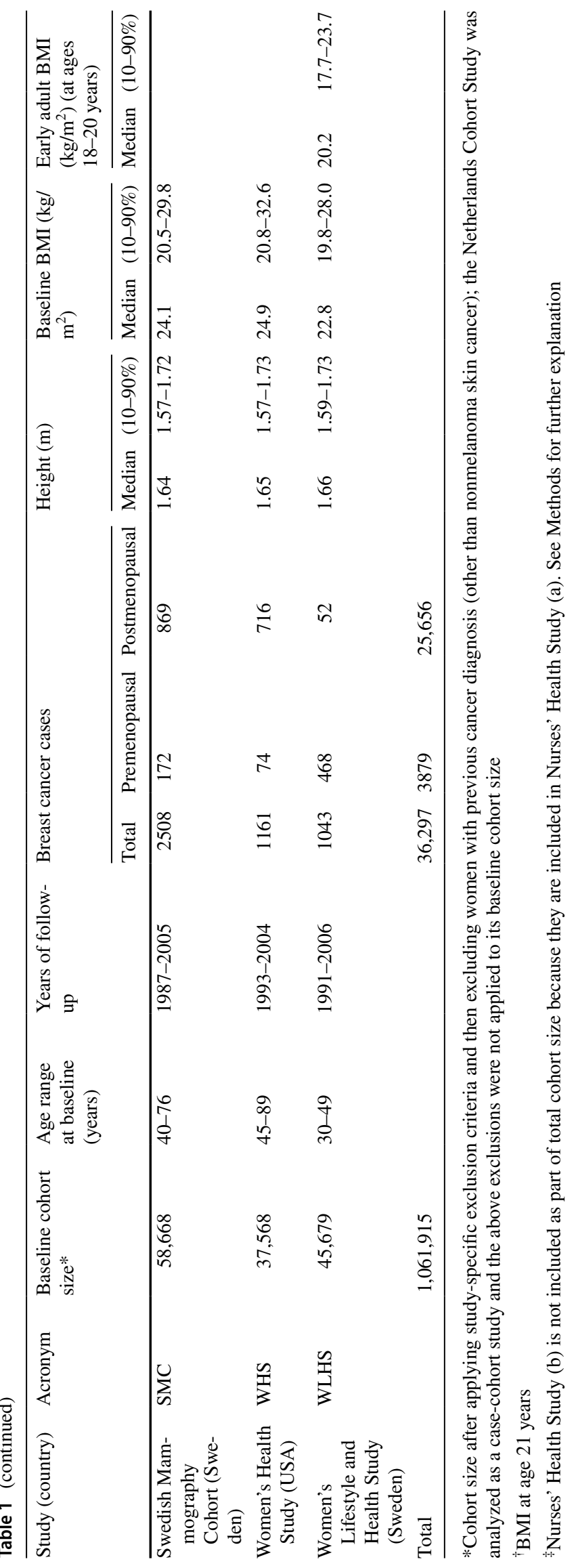



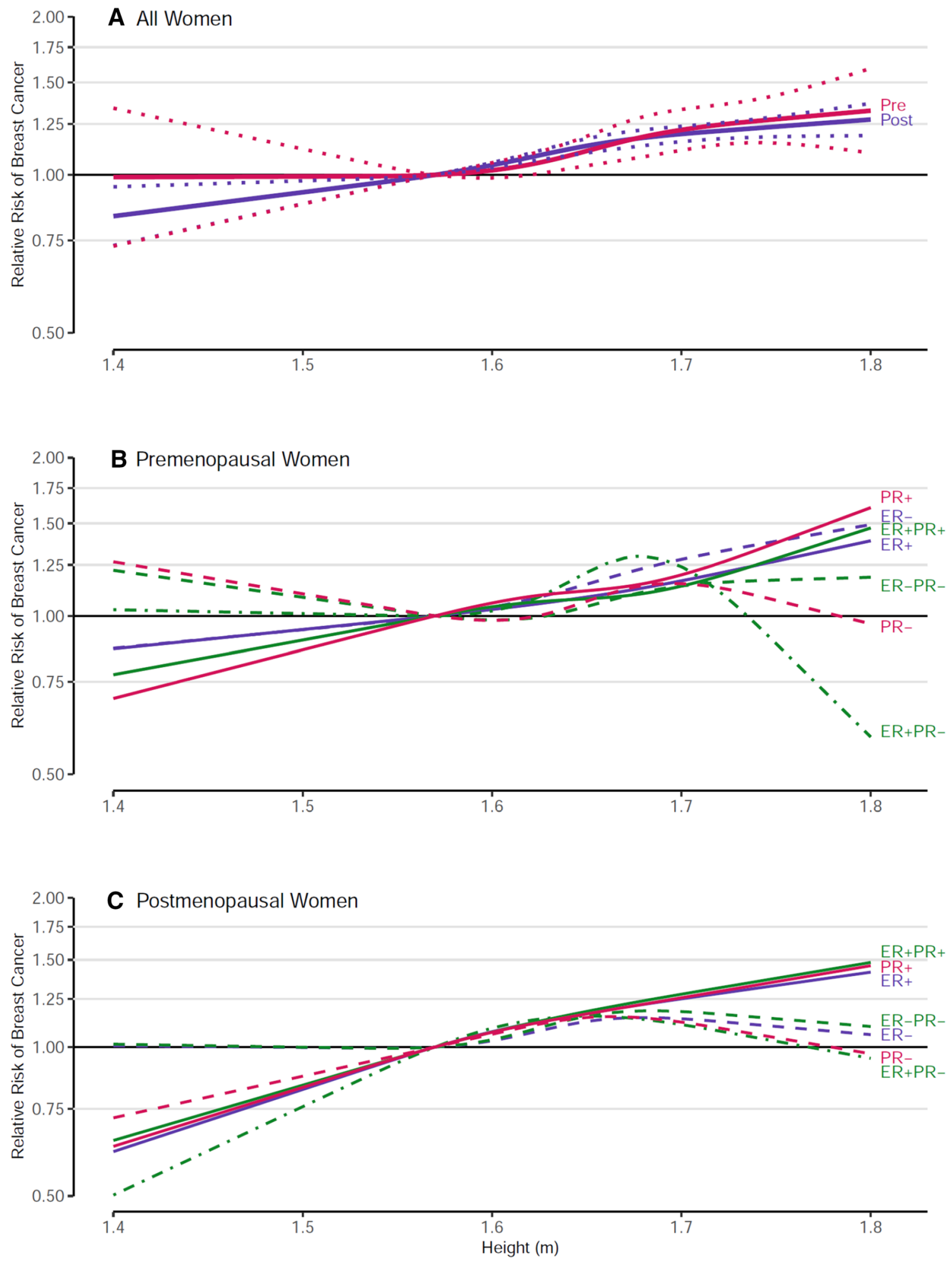

\section{Statistical analyses}

Participants were excluded from these analyses if at baseline they reported a personal history of cancer except for non-melanoma skin cancer at baseline, if they had missing data on height or baseline weight or if their reported energy intake was greater than three standard deviations from the study-specific $\log _{\mathrm{e}}$-transformed mean energy intake of the baseline population (an exclusion applied to all cohorts in the DCPP [21]). 
४Fig. 1 Spline regression curves for the association between height and breast cancer risk, the Pooling Project of Prospective Studies of Diet and Cancer, with reference height $=1.57 \mathrm{~m}$. Panel A shows the associations for overall premenopausal breast cancer (pre (red); $p$ value, test for nonlinearity $=0.363$ ) and overall postmenopausal breast cancer (post (blue); $p$ value, test for nonlinearity $=0.147$ ). Solid lines represents point estimates and dotted lines represent $95 \%$ confidence intervals. Panel B shows the associations for premenopausal breast cancer subtypes defined by estrogen receptor (ER) and progesterone receptor (PR) status. The $p$ value, test for nonlinearity $=0.846$ for ER positive (ER+, blue solid line), 0.882 for ER negative (ER-, blue dashed line), 0.610 for PR+ (red solid line), 0.385 for PR- (red dashed line), 0.664 for $\mathrm{ER}+\mathrm{PR}+$ (green solid line), 0.232 for ER+ PR- (green dash-dotted line), and 0.683 for ER- PRbreast cancer (green dashed line). Panel $\mathrm{C}$ shows the associations for postmenopausal breast cancer subtypes defined by ER and PR status. The $p$ value, test for nonlinearity $=0.736$ for ER+ (blue solid line), 0.247 for ER- (blue dashed line), 0.855 for PR+ (red solid line), 0.223 for PR- (red dashed line), 0.875 for ER+ PR+ (green solid line), 0.455 for ER+ PR- (green dash-dotted line), and 0.248 for ER- PR- breast cancer (green dashed line). Models were adjusted for ethnicity (Caucasian, African-American, Hispanic, Asian, others), family history of breast cancer (yes, no), personal history of benign breast disease (yes, no), alcohol consumption (non-drinkers, $>0-<5,5-<15,15-<30, \geq 30 \mathrm{~g} /$ day), smoking status (never, past, current), education ( $<$ high school, high school, $>$ high school), physical activity (low, medium, high), age at menarche $(<11,11-12$, $13-14, \geq 15$ years $)$, baseline BMI $(<23,23-<25,25-<30, \geq 30 \mathrm{~kg} /$ $\mathrm{m}^{2}$ ), oral contraceptive use (never, ever), hormone replacement therapy (never, ever), energy intake ( $\mathrm{kcal} / \mathrm{d}$, continuous), interaction between parity $(0,1-2, \geq 3)$ and age of first birth $(<30, \geq 30$ years); age at baseline in years and year of questionnaire return were included as stratification variables

Study-specific relative risks (RRs) and 95\% confidence intervals (CIs) for total, ER-, ER+, PR- and PR+ BC, and joint ER/PR subtypes, were estimated separately in each study by fitting Cox proportional hazards models [45]. No estimates were calculated for the ER- PR+ subtype due to insufficient case numbers. Cohorts were excluded from analyses of a receptor subtype if there were $<25$ cases with that subtype. We calculated person-years of follow-up from the date of questionnaire completion (baseline) to the date of diagnosis of first incident invasive BC, death, loss to follow up, or end of follow-up, whichever came first. We modeled age at baseline (in years) and year of questionnaire completion as stratification variables to adjust simultaneously for age, calendar time, and time since entry into the study [21]. We analyzed the NLCS as a case-cohort study because questionnaires were processed for only the cases and a random sample of the total cohort [46]. As before [47], we analyzed the NHS as two different cohorts (1980-1986, NHS[a]; 1986-2006, NHS[b]) to utilize the comprehensive dietary assessment administered in 1986.

Anthropometric variables (height, baseline BMI, early adult BMI, adult weight change) were entered into models as categorical or, if not statistically significant non-linear, as continuous variables. Baseline BMI was included in the height models; height was included in the baseline BMI, early adult BMI, and adult weight change models. To avoid collider bias [48], baseline BMI was not included in the early adult BMI and adult weight change models. We evaluated whether the observed association between each anthropometric variable and $\mathrm{BC}$ risk was modified by menopausal status at diagnosis as estimated using a previously described algorithm based on age at diagnosis [49]. Because postmenopausal hormone replacement therapy (HRT) modifies the relationship between adiposity and BC [6], we also performed analyses for postmenopausal BC according to HRT use (never vs. ever, at baseline). We used meta-regression to test for interactions by menopausal status and HRT use.

In all analyses presented, associations were essentially similar in age-adjusted and multivariable models; therefore, we only present the multivariable results. Multivariable RRs were adjusted for ethnicity, age at menarche, parity, age at first birth, HRT use (for analyses not stratified on this variable), oral contraceptive use, history of benign breast disease, family history of $\mathrm{BC}$, smoking status, education, physical activity, alcohol and energy intake (covariate categories are presented in table footnotes and figure legends). For each covariate, we created a missing indicator variable since the proportion of missing data in these cohorts is generally low [21]. We either adjusted for the abovementioned covariates directly in the model or we adjusted for confounders using the propensity score method $[50,51]$ when the number of cases of the outcome evaluated within a study was $<200$.

We pooled the study-specific RRs weighted by the inverse of their variances using a random effects model $[52,53]$ and tested for between-studies heterogeneity using the Q statistic [53]. To test for trend across categories of anthropometric variables, we assigned each category its median value and modeled that variable as a continuous term. We used a contrast test [54] to examine whether the associations differed significantly for BC subtypes defined by hormone receptor status (ER- vs. ER+; PR- vs. PR+; ER- PR- vs. ER+ $\mathrm{PR}-\mathrm{vs}$. ER+ PR+). All statistical tests were two-sided with a $p$ value of 0.05 as significance level, and were conducted using SAS (SAS Institute, Inc., Version 9.4, Cary, NC).

We estimated dose-response relationships of anthropometric variables with BC (subtypes) and tested for nonlinear associations using restricted cubic splines [55] with four knots (placed at the 5th, 35th, 65th, and $95^{\text {th }}$ percentiles). In these analyses, we combined all studies into one aggregated dataset, stratified by study, age at baseline, and year of baseline questionnaire, and adjusted for the abovementioned confounding variables. We excluded the top and bottom $1 \%$ of the data from the analysis, truncated the spline presentations at $1 \%$ and $99 \%$ of the distribution, and used approximately the median value for the referent category in the categorical analysis as the spline referent. To assess non-linearity, we used a likelihood ratio test to compare the model including the linear and cubic spline terms with the 

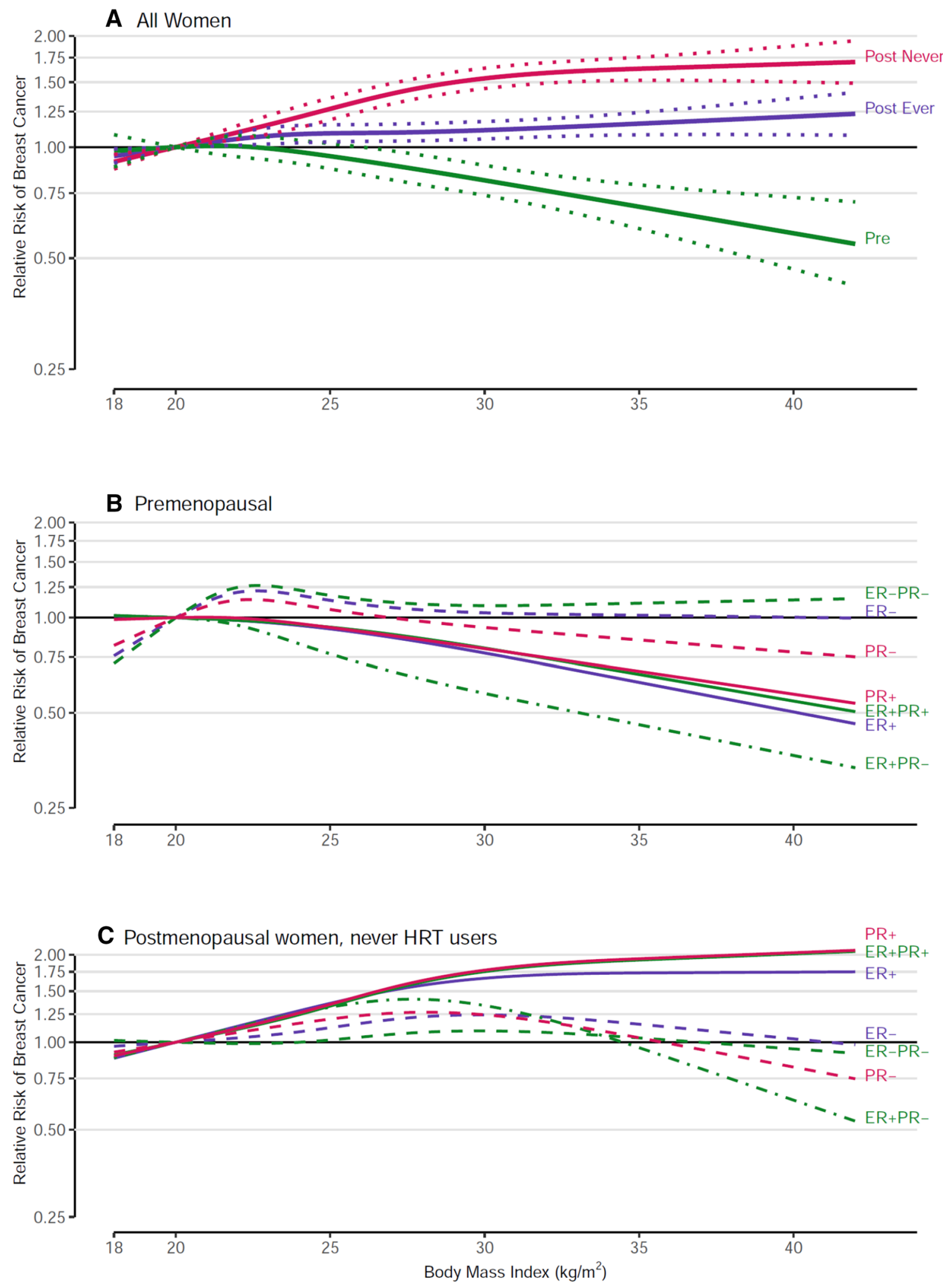

model including only the linear term for the anthropometric variable of interest. If the assumption of linearity held for the association between the anthropometric variable and $\mathrm{BC}$ risk, we further analyzed that anthropometric variable as a continuous variable. 
४Fig. 2 Spline regression curves for the association between body mass index at baseline and breast cancer risk, the Pooling Project of Prospective Studies of Diet and Cancer, with reference $20 \mathrm{~kg} / \mathrm{m}^{2}$. Panel A shows the associations for overall premenopausal breast cancer (pre; $p$ value, test for nonlinearity $=0.150$ ), overall postmenopausal breast cancer among never users of hormone therapy (post never; $p$ value, test for nonlinearity $<0.001$ ), and overall postmenopausal breast cancer among ever users of hormone therapy (post ever; $p$ value, test for nonlinearity $=0.208$ ). Panel B shows the associations for premenopausal breast cancer subtypes defined by estrogen receptor (ER) and progesterone receptor (PR) status. The $p$ value, test for nonlinearity $=0.371$ for $\mathrm{ER}+, 0.043$ for $\mathrm{ER}-, 0.484$ for $\mathrm{PR}+, 0.111$ for $\mathrm{PR}-, 0.512$ for $\mathrm{ER}+\mathrm{PR}+, 0.911$ for $\mathrm{ER}+\mathrm{PR}-$, and 0.084 for ER- PR- breast cancer. Panel C shows the associations for postmenopausal breast cancer subtypes defined by ER and PR status among never users of hormone therapy. The $p$ value, test for nonlinearity $=<0.001$ for $\mathrm{ER}+, 0.138$ for $\mathrm{ER}-,<0.001$ for $\mathrm{PR}+$, $<0.001$ for PR-, $<0.001$ for ER+ PR+, $<0.001$ for ER+ PR-, and 0.558 for ER- PR - breast cancer. Models were adjusted for ethnicity (Caucasian, African-American, Hispanic, Asian, others), family history of breast cancer (yes, no), personal history of benign breast disease (yes, no), alcohol consumption (non-drinkers, $>0-<5,5-<15$, $15-<30, \geq 30 \mathrm{~g} /$ day), smoking status (never, past, current), education ( $<$ high school, high school, $>$ high school), physical activity (low, medium, high), age at menarche $(<11,11-12,13-14, \geq 15$ years $)$, height $(<1.60,1.60-<1.65,1.65-<1.70,1.70-<1.75, \geq 1.75 \mathrm{~m})$, oral contraceptive use (never, ever), energy intake (kcal/d, continuous), interaction between parity $(0,1-2, \geq 3)$ and age of first birth $(<30, \geq 30$ years); age at baseline in years and year of questionnaire return were included as stratification variables

\section{Results}

In the 20 prospective cohorts with follow-up 8 to 26 years, 36,297 incident invasive BC cases (3879 premenopausal and 25,656 postmenopausal) were identified among 1,061,915 women (Table 1). ER receptor status was known for $71.9 \%$ of cases, PR status for $68.7 \%$ of cases (Supplementary Table 1). Of the premenopausal cases with known receptor status, the percentages with $\mathrm{ER}+, \mathrm{PR}+, \mathrm{ER}+\mathrm{PR}+$, and ER- PR- status were $72 \%, 69 \%, 62 \%$, and $21 \%$, respectively. For postmenopausal cases, the percentages with ER+, $\mathrm{PR}+, \mathrm{ER}+\mathrm{PR}+$, and $\mathrm{ER}-\mathrm{PR}-$ status were $82 \%, 70 \%, 68 \%$, and $15 \%$, respectively.

Median height ranged from $1.52 \mathrm{~m}$ in the Japanese JPHC1 to $1.66 \mathrm{~m}$ in the Swedish WLHS. Median baseline BMI ranged from $22.8 \mathrm{~kg} / \mathrm{m}^{2}$ in women aged 30-49 years in WLHS to $26.2 \mathrm{~kg} / \mathrm{m}^{2}$ in women aged 55-74 years in the US PLCO. Among the cohort studies with available data, median early adult BMI differed by only $1 \mathrm{~kg} / \mathrm{m}^{2}$ across studies (Table 1).

\section{Height}

Height was statistically significantly positively associated with both premenopausal and postmenopausal BC risk (Fig. 1; Supplementary Table 2). Restricted cubic spline regression analyses showed no significant deviation from linearity for these associations ( $p$ values, test for nonlinearity $\geq 0.14$, Fig. 1). In continuous analyses, the RRs (95\%CI) per $5 \mathrm{~cm}$ increment were similar in premenopausal and postmenopausal women: 1.07 (1.04-1.10) and 1.06 (1.05-1.08), respectively (Supplementary Table 2 ). There was no significant heterogeneity in RR estimates between the cohort studies, nor any significant interaction by menopausal status or by HRT use in postmenopausal women ( $p$ values, tests for interaction, 0.750 and 0.212 , respectively).

For height, stronger positive associations were generally seen with hormone receptor-positive subtypes than with receptor-negative subtypes for both premenopausal and postmenopausal BC, except for ER+ and ER- premenopausal BC (Fig. 1, Supplementary Table 2). For postmenopausal BC, all tests for differences between subtypes defined by ER and/or PR status were significant in continuous analyses (all $p$ values $<0.03$, Supplementary Table 2). For both premenopausal and postmenopausal BC, relative to heights of $1.55-<1.60 \mathrm{~m}$, risk for women $\geq 1.75 \mathrm{~m}$ was approximately $40-50 \%$ higher for receptor-positive subtypes, but only $20 \%$ higher for receptor-negative subtypes (except a $40 \%$ increased risk was seen for premenopausal ER-subtype).

\section{Baseline BMI}

Baseline (adult) BMI was strongly inversely related to premenopausal BC risk, strongly positively related to postmenopausal BC risk in HRT never-users, and only modestly positively related to postmenopausal BC risk in ever HRT users (all $p$ trend <0.001) (Fig. 2a; Supplementary Table 3), with significant interaction by menopausal status $(p<0.001)$ and HRT use $(p<0.001)$. Spline regression analyses showed a steady decline in risk with increasing baseline $\mathrm{BMI}$ in premenopausal women, but a plateau in increasing risk at a BMI of $\sim 30 \mathrm{~kg} / \mathrm{m}^{2}$ in postmenopausal never HRT users (p-nonlinearity $<0.001$ ). Comparing women with $\mathrm{BMI} \geq 30 \mathrm{~kg} / \mathrm{m}^{2}$ to women with BMI $<21 \mathrm{~kg} / \mathrm{m}^{2}$, the RR (95\%CI) was $0.78(0.64-0.93)$ for premenopausal BC, 1.61 (1.45-1.79) for postmenopausal BC in HRT never-users, and 1.17 (1.09-1.25) for postmenopausal HRT ever-users. There was no significant heterogeneity between the cohort studies for premenopausal $\mathrm{BC}$ or for postmenopausal $\mathrm{BC}$ in never or ever HRT users.

For premenopausal $\mathrm{BC}$, the strong inverse association with baseline BMI was more pronounced for receptor-positive subtypes (all p-trend $<0.001$ ) but flattened out and was not statistically significant for receptor-negative subtypes (Fig. 2b, Supp Table 3). Comparing BMI $\geq 30$ to $<21 \mathrm{~kg} / \mathrm{m}^{2}$, $32-33 \%$ significantly lower risks were observed for ER+, $\mathrm{PR}+$ and ER+ PR+ subtypes. For the same contrast, the 

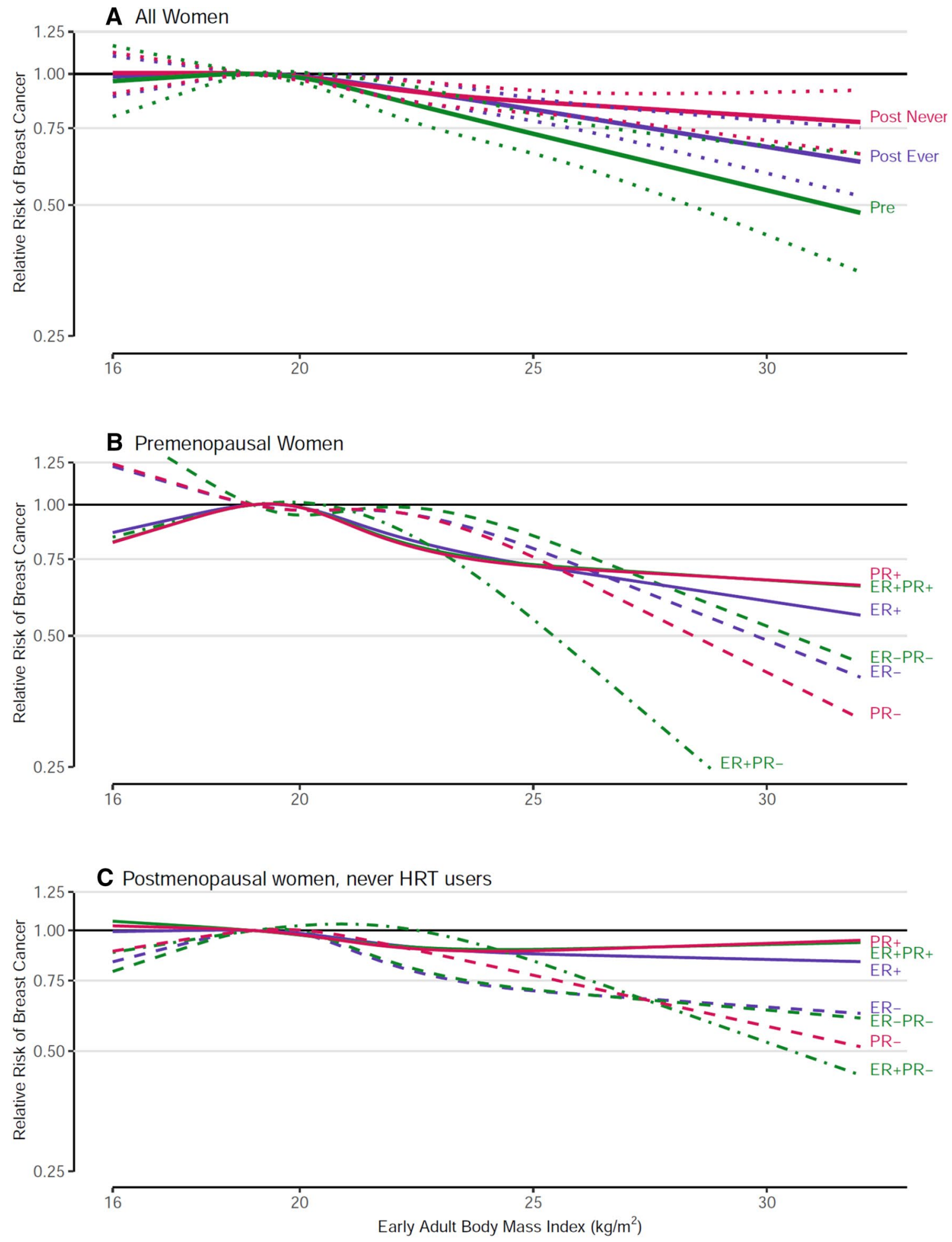

Fig. 3 Spline regression curves for the association between early adulthood body mass index and breast cancer risk, the Pooling Project of Prospective Studies of Diet and Cancer, with reference $19 \mathrm{~kg} /$ $\mathrm{m}^{2}$. Panel A shows the associations for overall premenopausal breast cancer (pre; $p$ value, test for nonlinearity $=0.088$ ), overall postmenopausal breast cancer among never users of hormone therapy (post never; $p$ value, test for nonlinearity $=0.509$ ), and overall postmenopausal breast cancer among ever users of hormone therapy (post ever; $p$ value, test for nonlinearity $=0.068$ ). Panel $\mathrm{B}$ shows the associations for premenopausal breast cancer subtypes defined by estrogen recep- tor (ER) and progesterone receptor (PR) status. The $p$ value, test for nonlinearity $=0.090$ for $\mathrm{ER}+, 0.469$ for $\mathrm{ER}-, 0.047$ for $\mathrm{PR}+, 0.271$ for PR-, 0.074 for $\mathrm{ER}+\mathrm{PR}+, 0.178$ for $\mathrm{ER}+\mathrm{PR}-$, and 0.347 for ER-PR- breast cancer. Panel C shows the associations for postmenopausal breast cancer subtypes defined by ER and PR status among never users of hormone therapy. The $p$ value, test for nonlinearity $=0.544$ for $E R+, 0.130$ for $E R-, 0.305$ for $P R+, 0.074$ for PR-, 0.390 for $\mathrm{ER}+\mathrm{PR}+, 0.060$ for $\mathrm{ER}+\mathrm{PR}-$, and 0.116 for ER-PRbreast cancer. Models were adjusted for the same factors as in Fig. 2 

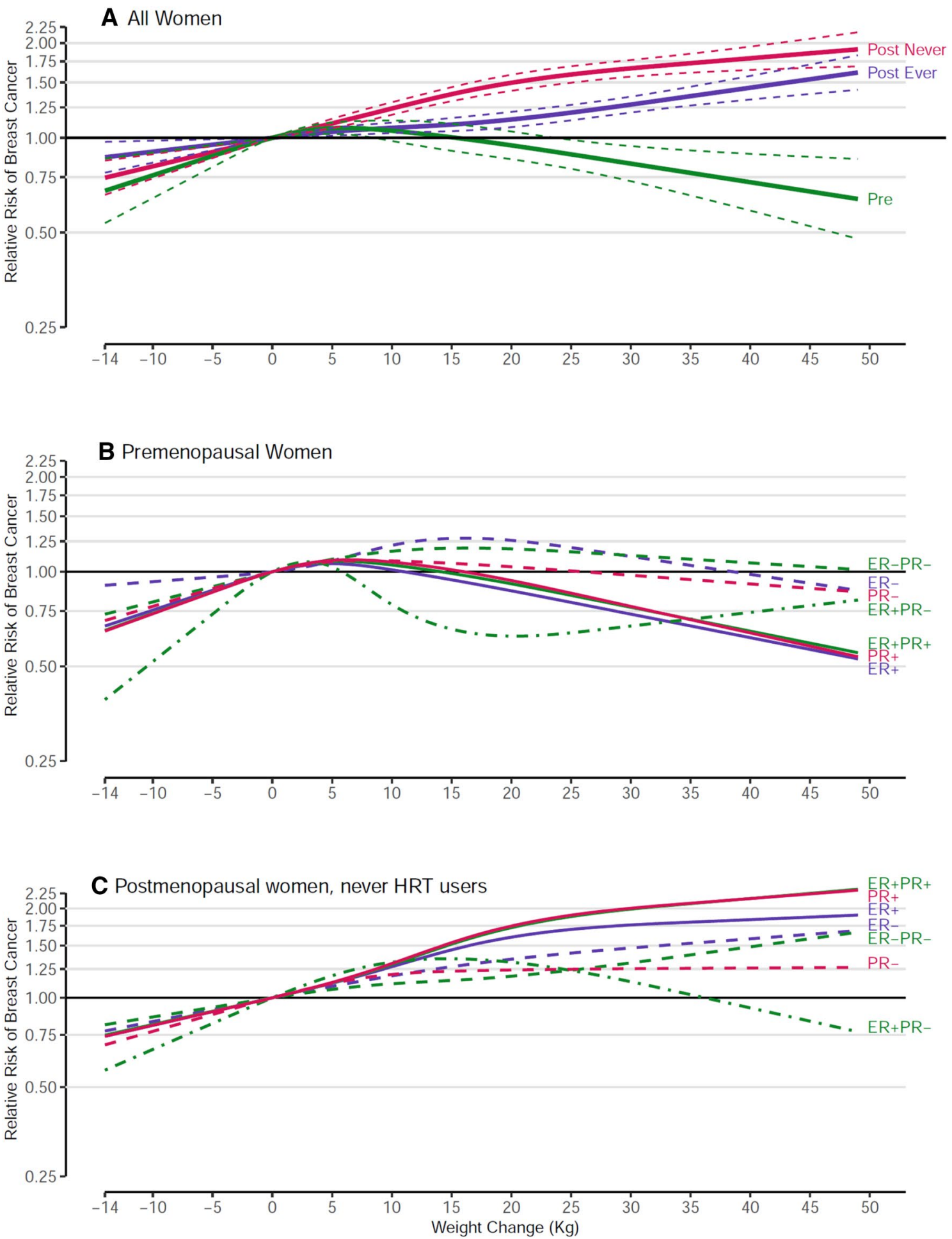

Fig. 4 Spline regression curves for the association between weight change and breast cancer risk, the Pooling Project of Prospective Studies of Diet and Cancer, with reference $0 \mathrm{~kg}$. Panel A shows the associations for overall premenopausal breast cancer (pre; $p$ value, test for nonlinearity $<0.001$ ), overall postmenopausal breast cancer among never users of hormone therapy (post never; $p$ value, test for nonlinearity $<0.001$ ), and overall postmenopausal breast cancer among ever users of hormone therapy (post ever; $p$ value, test for nonlinearity $=0.279$ ). Panel B shows the associations for premenopausal breast cancer subtypes defined by estrogen receptor (ER) and progesterone receptor (PR) status. The $p$ value, test for nonlinearity $<0.001$ for $\mathrm{ER}+, 0.124$ for $\mathrm{ER}-,<0.001$ for $\mathrm{PR}+, 0.222$ for PR-, $<0.001$ for $\mathrm{ER}+\mathrm{PR}+, 0.059$ for $\mathrm{ER}+\mathrm{PR}-$, and 0.402 for $\mathrm{ER}-\mathrm{PR}-$ breast cancer. Panel $\mathrm{C}$ shows the associations for postmenopausal breast cancer subtypes defined by ER and PR status among never users of hormone therapy. The $p$ value, test for nonlinearity $<0.001$ for $\mathrm{ER}+, 0.630$ for $\mathrm{ER}-,<0.001$ for $\mathrm{PR}+, 0.036$ for $\mathrm{PR}-, 0.003$ for $\mathrm{ER}+\mathrm{PR}+,<0.001$ for ER+ PR-, and 0.874 for ER- PR- breast cancer. Models were adjusted for the same factors as in Fig. 2 
comparable RRs were not significant: 0.97 for PR-, 1.00 for ER-, and 1.19 for ER- PR- tumors.

For postmenopausal women who never used HRT, stronger positive associations with baseline BMI that plateaued around $30 \mathrm{~kg} / \mathrm{m}^{2}$ were seen for receptor-positive subtypes (all p-nonlinearity <0.001) (Fig. 2c, Supp Table 3). RRs ranged from 1.69 to 1.95 comparing $\mathrm{BMI} \geq 30$ vs. $<21 \mathrm{~kg} / \mathrm{m}^{2}$ (all p-trend $<0.001$ ). However, with receptor-negative subtypes, risk increased slightly and then declined with the comparable RRs ranging from 1.03 to 1.12 (Fig. 2c, Supp Table 3). Even with at least 1000 cases of each receptor-negative subtype, none of these RR point estimates was significant (all $\mathrm{p}$ for common effects by receptor status $\leq 0.002$ ).

\section{Early adult BMI}

Early adult BMI was significantly inversely related to both premenopausal and postmenopausal BC (never and ever HRT users) risk, and associations were stronger for premenopausal BC (p-interaction by menopausal status 0.002 for continuous early adult BMI, Supplementary Table 4). In postmenopausal women, interaction with HRT use was not significant $(p=0.618)$. Restricted cubic spline analyses showed no significant deviations from linearity for premenopausal and postmenopausal BC among never HRT users and among ever HRT users (Fig. 3), overall or for most subtypes. Associations were moderately to strongly inverse with no significant heterogeneity between cohort studies. Per increment of $5 \mathrm{~kg} / \mathrm{m}^{2}$, the RR $(95 \% \mathrm{CI})$ was $0.79(0.74-0.84)$ for premenopausal, and $0.89(0.85-0.92)$ for postmenopausal $\mathrm{BC}$ in never HRT users. The inverse associations appeared somewhat stronger for receptor-negative than for receptorpositive subtypes. However, these differences were only significant for PR status for postmenopausal BC among never HRT users (p-common effects $=0.020$ ), (Fig. 3, Supplementary Table 4).

\section{Adult weight change}

Adult weight change between age 18-20 and age at study enrollment was not significantly associated with premenopausal BC risk but significantly positively associated with postmenopausal BC risk in both never and ever HRT users (both p-trend <0.001) (Fig. 4a, Supp Table 5). Interaction by menopausal status was significant $(p<0.001)$. Postmenopausal women with a weight gain of $\geq 20 \mathrm{~kg}$, compared to women with stable weight (defined as a change of $2 \mathrm{~kg}$ or less), had a $68 \%$ increased risk of BC in never HRT users, and a $22 \%$ increased risk in ever HRT users (p-interaction by HRT use $<0.001$ ). Spline regression analyses confirmed significant nonlinearity for premenopausal BC and postmenopausal BC in never HRT users, but not for postmenopausal
BC in ever HRT users. In continuous analyses, the RR $(95 \%$ CI) was 1.09 (1.06-1.12) per increment of $10 \mathrm{~kg}$ for postmenopausal BC in ever HRT users. Estimates were essentially similar when early adult BMI was included in the models (data not shown). Compared to women maintaining a stable weight, women who had lost $>2 \mathrm{~kg}$ had nonsignificant 9-10\% lower risk of both overall premenopausal and postmenopausal BC (Supplementary Table 5).

For premenopausal BC, spline regression analyses showed evidence of nonlinear relationships with weight change for hormone receptor-positive subtypes, with risk increasing and then decreasing, and no associations with receptor-negative subtypes (Fig. 4b, Supplementary Table 5). For postmenopausal BC among never HRT users, significant positive associations with weight change were seen for all receptor subtypes (all p-trend $\leq 0.04$ ); there was evidence for nonlinearity for nearly all subtypes (Fig. 4c, Supplementary Table 5). Positive associations were substantially stronger for receptor-positive subtypes, with an increased risk of approximately 70-90\% associated with a weight gain of $\geq 20 \mathrm{~kg}$, relative to stable weight, compared to $10-40 \%$ for receptor-negative subtypes.

\section{Joint effect of early adult BMI and adult weight change}

To examine whether the association between adult weight change and subsequent BC risk depended on BMI in early adulthood, we conducted analyses of adult weight change stratified by early adult BMI (Supplementary Table 6). For these analyses, the group of women was split at early adult BMI of $21 \mathrm{~kg} / \mathrm{m}^{2}$ (close to the median of BMI age 18-20 years across the cohort studies), and the common reference category was the group of women with early adult $\mathrm{BMI}<21 \mathrm{~kg} / \mathrm{m}^{2}$, and stable weight. For premenopausal BC, and its ER+ subtype, risk was decreased at $\geq 20 \mathrm{~kg}$ weight gain; for the ER- subtype there was essentially no association. There was no evidence of interaction between early adult BMI and weight change. Women heavier in early adulthood generally have reduced premenopausal BC risk, relative to those leaner in early adulthood, independent of adult weight change.

Postmenopausal BC risk was strongly related to weight change in both strata of early adult BMI among women who never used HRT (both p-trend $<0.001$ ). The positive association was more pronounced for women who were leaner in early adult life (BMI $18<21$ ), with a $79 \%$ increased risk for those who gained $\geq 20 \mathrm{~kg}$ compared to women with stable weight (p-interaction $=0.018$ ). For ER+ postmenopausal BC, the same pattern was observed with a significant interaction $(\mathrm{p}$-interaction $=0.034)$. For both overall and $\mathrm{ER}+\mathrm{BC}$, risk was noticeably lower (approximately 20-35\% reduction) among women who were leaner in early adult life and lost $>2 \mathrm{~kg}$, whereas risk was only slightly reduced 
(by $<10 \%$ ) among women with a comparable weight loss who were heavier in early adult life. For ER- BC, weight change was only significantly positively associated in women with early adult $\mathrm{BMI}<21 \mathrm{~kg} / \mathrm{m}^{2}$ (p-trend $<0.001$ ); no clear relationship was seen in women with early adult BMI $\geq 21 \mathrm{~kg} / \mathrm{m}^{2}$ (p-interaction $\left.=0.133\right)$.

\section{Discussion}

Height showed positive, linear associations for premenopausal and postmenopausal BC risk, with stronger associations for hormone receptor-positive subtypes. Baseline (adult) BMI had inverse associations with premenopausal BC, with stronger associations for receptor-positive subtypes. Positive nonlinear associations between baseline BMI and postmenopausal BC risk were found in women who never used HRT, primarily for receptor-positive subtypes; positive associations were more modest in HRT users than never users. Early adult BMI was inversely related to both premenopausal and postmenopausal $\mathrm{BC}$ risk with suggestively stronger associations shown for receptor-negative subtypes. Adult weight gain since age 18-20 years was positively associated with postmenopausal $\mathrm{BC}$ risk; the association was substantially stronger for receptor positive subtypes, and among women who were leaner in early adulthood. Women who had lost weight since age 18-20 years had a suggestively lower risk of overall premenopausal or postmenopausal BC compared to women with stable weight. Women heavier in early adulthood generally had reduced premenopausal BC risk, relative to those leaner in early adulthood, independent of adult weight change.

This large pooled analysis of prospective studies provides the most detailed examination of individual height, weight and adult weight change in relation to postmenopausal BC risk overall and by hormone receptor subtype. Further strengths of this analysis include use of standardized exposure and confounder information, examination of overall premenopausal $\mathrm{BC}$ and receptor subtypes and use of a standardized (dose-response) modeling approach across outcomes and populations. Unlike meta-analyses of published results on these topics which have often reported heterogeneity between studies (e.g. [11, 20]), our analysis generally showed little heterogeneity between cohorts after stratifying by menopausal status, HRT use, and ER/PR subtypes. Our study enabled us to conduct more detailed dose-response modelling, particularly for BC subtypes, than was accomplished in many other studies, including meta-analyses. This is especially important when relationships are nonlinear, as we observed for baseline BMI and weight gain with postmenopausal BC risk in women who never used HRT and for weight gain with (hormone receptor-positive subtypes of) premenopausal $\mathrm{BC}$.

\section{BMI at baseline (generally in mid to later adulthood)}

While our current analysis confirms the stark contrasting associations between baseline BMI and risk of premenopausal (inverse association) versus postmenopausal BC (positive association) [1, 2, 6, 7, 56-59], and stronger positive associations with postmenopausal $\mathrm{BC}$ in never compared to ever HRT users [7, 56, 60], we also showed that the dose-response relationship with postmenopausal BC and its subtypes was significantly nonlinear in never HRT users. As in recent meta-analyses [19, 20], including at most half of the studies in our present analysis, we now showed relatively strong positive associations with ER and/or PR positive subtypes $(\mathrm{ER}+, \mathrm{PR}+, \mathrm{ER}+\mathrm{PR}+$ ) of postmenopausal $\mathrm{BC}$, and no statistically significant associations with receptor-negative subtypes. In contrast to meta-analyses which can often be hampered by heterogeneity in the study-specific results [7, 20, 57], we observed no significant heterogeneity among the cohorts after taking into account menopausal status and HRT use, illustrating the potential of more precise pooled analyses.

Regarding the association of overweight in later adult life with postmenopausal $\mathrm{BC}$ risk, the most plausible mechanism is hormone-related. When ovarian estrogen production is decreased after menopause, adipose tissue again becomes a major source of estrogen due to aromatization of androgens in peripheral adipose tissue [61]. Together with reduced production of sex hormone binding globulin due to obesity, this leads to increased levels of circulating bioavailable estrogens. Support for the mediating role of estrogens comes from observations that the association between BMI and postmenopausal $\mathrm{BC}$ was essentially eliminated after adjustment for bioavailable estrogen concentration [14, 15, 58]. Furthermore, the substantially weakened association with BMI in HRT users also indicates that this exogenous hormone source overrides the effect of endogenous estrogen production from peripheral fat tissue. Thus, the association of postmenopausal BC with BMI is most visible in never HRT users, and indeed specifically with hormone receptor positive subtypes. Alternative potential biological mechanisms include altered production of adipokines, excess activation of the IGF axis, and chronic low-grade inflammation [62-64].

For BMI and premenopausal BC, we found stronger inverse associations than previously reported in metaanalyses [7, 20, 57]; our results were similar to those of a recent pooled analysis focused on premenopausal BC (8 studies in our analyses overlapped with that pooled analysis) [8]. We also showed stronger inverse associations with hormone receptor-positive subtypes, and no significant 
association with receptor-negative subtypes of premenopausal BC, as has also been seen in meta-analyses of cohort and case-control studies combined [6, 19]. For the inverse association between BMI and premenopausal BC risk, several mechanisms have been proposed but none has been widely accepted. In premenopausal women, obesity may protect against $\mathrm{BC}$ by causing more frequent anovulatory menstrual cycles $[65,66]$. This would result in decreased estradiol and progesterone exposure and lower luteal phase progesterone levels in ovulatory cycles [67]. Although this is not supported by studies that have adjusted for menstrual cycle pattern [68-70], our observation that BMI is more strongly related to hormone-dependent ER/PR positive BCs nevertheless suggests a hormonal mechanism is partly responsible. Other proposed mechanisms include mitigation of estrogen-induced proliferation in breast epithelial cells concentrations in premenopausal women by decreased progesterone [20]. Gene expression studies showed decreased $\mathrm{BC}$ cell proliferation in premenopausal women with increasing body weight, but increased in postmenopausal women $[20,71]$. More research is needed to elucidate this intriguing inverse association of BMI with premenopausal BC.

\section{Early adult BMI}

Intriguingly, BMI at early adult age (18-20 years) seems consistently inversely related to both premenopausal and postmenopausal BC risk, as is evident from our pooled analysis, and from meta-analyses of cohort studies [11, 20]. Unlike results from meta-analyses [11, 20], there was no statistically significant heterogeneity in our cohort estimates. Also, our estimated association regarding premenopausal $\mathrm{BC}\left(\mathrm{RR}=0.79\right.$ per $\left.5 \mathrm{~kg} / \mathrm{m}^{2}\right)$ was more strongly inverse than in the meta-analyses [11, 20], and comparable to a recently published estimate from a pooled analysis of premenopausal BC [8]. This latter study showed that BMI at ages 18-24 years was most strongly inversely related to premenopausal BC, compared to BMI measured at ages 25-54 years. Although both that pooled study and our study reported no significant differences in associations across tumor subtypes defined by hormone receptor status, we noted that stronger associations were suggested for receptor-negative subtypes for both premenopausal and postmenopausal BC. For postmenopausal BC, we also observed that the inverse associations were statistically significant for all ER/PR subtypes except ER+ PR-, a subtype with relatively few cases.

A possible explanation for the intriguing inverse association of early BMI and BC was given in a Finnish study, which found that BMI at age 7 years showed a stronger inverse association with BC than BMI at age 15 [72], which is in line with the observation that BMI at ages 18-24 years had a stronger inverse relationship with BC than BMI measured at later ages [8]. BMI is an indicator of estrogenicity in childhood, especially before puberty, when adipose tissue is the major source of estrogens [72]. Mammary glands may differentiate early in animals exposed to estrogens early in life, and therefore become less susceptible to carcinogens [72-74]. Increased estrogenicity resulting from childhood overweight or obesity, especially before puberty, possibly also induces early human breast differentiation [72], and thus could possibly lead to reduced BC risk later. Other mechanisms related to IGF1 are also possible, since it has been found that higher BMI in childhood/adolescence was associated with decreased insulin-like growth factor1 (IGF1) levels in adult women $[11,75]$. Because the mechanism for a protective effect of early adiposity on $\mathrm{BC}$ remains uncertain, more research is needed to obtain further mechanistic insight.

\section{Adult weight change}

Our results on weight change and postmenopausal BC generally agree with results from a recent meta-analysis [20], although we found positive associations with all postmenopausal ER/PR subtypes instead of only receptor-positive subtypes [20]. After stratification by early adult BMI, we found that adult weight gain after ages 18-20 years was more important for determining postmenopausal BC risk (especially in never HRT users) than early adult BMI, with the strongest positive effect of weight gain observed in women with early adult $\mathrm{BMI}<21 \mathrm{~kg} / \mathrm{m}^{2}$. In line with these results, Song et al. [63] observed in an analysis of body shape trajectories across the lifespan and cancer risk, that women who were lean in adolescence and gained weight later in life had a significantly higher postmenopausal $\mathrm{BC}$ risk than stable lean women. Furthermore, women with a heavier body shape in early life showed a lower risk of total and obesity-related cancer than women with a leaner body shape, which seemed to be mainly due to postmenopausal BC [63]. For premenopausal BC, early adult BMI seemed to be more important for the inverse association than adult weight gain.

\section{Height}

Our results showing moderately strong, positive, linear associations of height and $\mathrm{BC}$ risk are consistent with earlier studies and meta-analyses [1, 3-5, 41]. In a meta-analysis of 26 cohort studies, height was positively associated with premenopausal and postmenopausal BC [5]; the strength of the associations was comparable to our current results. That meta-analysis also reported stronger associations for hormone receptor positive subtypes, but did not distinguish premenopausal from postmenopausal BC. We found generally stronger associations for receptor-positive subtypes (particularly PR+) for both premenopausal and postmenopausal $\mathrm{BC}$, but these differences were only statistically significant 
in postmenopausal BC, possibly due to lower numbers of premenopausal BCs. Some evidence suggests that height is positively associated with PR expression in normal breast tissue [76]. The association of height with $\mathrm{BC}$ risk was also confirmed in Mendelian randomization analysis [5], underscoring the strong and consistent evidence for height as a risk factor for BC.

Attained adult height is genetically and environmentally determined. Recent results from the Netherlands Cohort Study show that women who were exposed to energy restriction (i.e. father unemployed vs. employed) during the Economic Depression (1932-1940) before or during their growth spurt, were significantly shorter than those without this exposure (163.8 cm vs. $165.5 \mathrm{~cm}$, respectively) [41]. In that study, energy restriction before and/or during the pubertal growth spurt was associated with a decreased hormone receptor-positive $\mathrm{BC}$ risk [41]. One mechanism as to why height increases BC risk involves the IGF signaling pathway as IGFs, and particularly IGF1, play important roles in growth and in carcinogenesis by inhibiting apoptosis and stimulating cell proliferation $[5,77-80]$.

\section{Study limitations}

Besides the abovementioned strengths of our study, potential weaknesses of our study include the use of self-reported height and weight in the majority of studies, the longer-term recall of early adult weight, the lack of detailed information on menopausal status and other covariates such as HRT use during follow-up, absence of weight information at ages other than early adulthood and cohort baseline, limited number of studies from continents other than North-America and Europe, and minimal race/ethnic diversity. The group of ever HRT users was heterogeneous regarding type of HRT used (which may be important for BC [81]), and consisted of past and current users because we had no updated information on use. In a recent pooled analysis, no association between $\mathrm{BC}$ risk and BMI was seen among current HRT users [81]. We also had no information on the mode of $\mathrm{BC}$ detection, whereas associations of BMI with $\mathrm{BC}$ may vary according to detection method [82].

\section{Conclusion}

In conclusion, associations between baseline (adult) BMI and adult weight change with risk of $\mathrm{BC}$ varied according to menopausal status, were often nonlinear, and stronger for hormone receptor-positive subtypes for both premenopausal and postmenopausal BC. Body height was linearly and positively associated with any BC risk, but stronger for receptor-positive subtypes. In contrast, the inverse and generally linear associations of early adult BMI with premenopausal and postmenopausal BC seemed stronger for receptornegative subtypes. The association of baseline (adult) BMI with postmenopausal BC risk was stronger in never HRT users than in ever users. If HRT use further decreases in the future, then BMI will become a more important, avoidable cause of postmenopausal BC [6]. More research is needed to identify mechanisms of action for the intriguing inverse association of BMI with premenopausal BC risk and the crossover of effects of BMI on premenopausal and postmenopausal BC risk, the inverse association of early adult BMI with premenopausal and postmenopausal $\mathrm{BC}$, and the positive association of height with premenopausal and postmenopausal BC risk.

Acknowledgements We thank the participants and staff of each of the cohorts for their valuable contributions and the organizations that funded the infrastructure for each cohort study. We thank Shiaw-Shyuan (Sherry) Yaun at the Harvard TH Chan School of Public Health for data management and statistical support.

Funding This work was supported by National Institutes of Health (Grant CA55075 to WCW), the Breast Cancer Research Foundation (to WCW) and the Intramural Research Program of the National Cancer Institute. Funding for the participating cohorts is included in Supplementary Table S7.

\section{Compliance with ethical standards}

Conflict of interest The authors declare no conflict of interest.

Ethics approval and consent to participate Each participating study has been approved by the local ethic committee. Informed consent was obtained from all individual participants included in each study.

Open Access This article is licensed under a Creative Commons Attribution 4.0 International License, which permits use, sharing, adaptation, distribution and reproduction in any medium or format, as long as you give appropriate credit to the original author(s) and the source, provide a link to the Creative Commons licence, and indicate if changes were made. The images or other third party material in this article are included in the article's Creative Commons licence, unless indicated otherwise in a credit line to the material. If material is not included in the article's Creative Commons licence and your intended use is not permitted by statutory regulation or exceeds the permitted use, you will need to obtain permission directly from the copyright holder. To view a copy of this licence, visit http://creativecommons.org/licenses/by/4.0/.

\section{References}

1. van den Brandt PA, Spiegelman D, Yaun SS, et al. A pooled analysis of prospective cohort studies on height, weight, and breast cancer risk. Am J Epidemiol. 2000;152(6):514-27.

2. Renehan AG, Tyson M, Egger M, Heller RF, Zwahlen M. Body-mass index and incidence of cancer: a systematic review and meta-analysis of prospective observational studies. Lancet. 2008;371(9612):569-78. https://doi.org/10.1016/S0140 $-6736(08) 60269-X$. 
3. Gunnell D, Okasha M, Smith GD, Oliver SE, Sandhu J, Holly JM. Height, leg length, and cancer risk: a systematic review. Epidemiol Rev. 2001;23(2):313-42.

4. Green J, Cairns BJ, Casabonne D, et al. Height and cancer incidence in the Million Women Study: prospective cohort, and meta-analysis of prospective studies of height and total cancer risk. Lancet Oncol. 2011;12(8):785-94. https://doi.org/10.1016/ S1470-2045(11)70154-1.

5. Zhang B, Shu XO, Delahanty RJ, et al. Height and breast cancer risk: evidence from prospective studies and mendelian randomization. J Natl Cancer Inst. 2015. https://doi.org/10.1093/jnci/ djv219.

6. Munsell MF, Sprague BL, Berry DA, Chisholm G, TrenthamDietz A. Body mass index and breast cancer risk according to postmenopausal estrogen-progestin use and hormone receptor status. Epidemiol Rev. 2014;36:114-36. https://doi.org/10.1093/ epirev/mxt010.

7. Chen Y, Liu L, Zhou Q, et al. Body mass index had different effects on premenopausal and postmenopausal breast cancer risks: a dose-response meta-analysis with 3,318,796 subjects from 31 cohort studies. BMC Public Health. 2017;17(1):936. https://doi.org/10.1186/s12889-017-4953-9.

8. Premenopausal Breast Cancer Collaborative G, Schoemaker MJ, Nichols HB, et al. Association of body mass index and age with subsequent breast cancer risk in premenopausal women. JAMA Oncol. 2018;4(11):e181771. https://doi.org/10.1001/ jamaoncol.2018.1771.

9. Michels KB, Terry KL, Eliassen AH, Hankinson SE, Willett WC. Adult weight change and incidence of premenopausal breast cancer. Int J Cancer. 2012;130(4):902-9. https://doi. org/10.1002/ijc.26069.

10. Ahn J, Schatzkin A, Lacey JV Jr, et al. Adiposity, adult weight change, and postmenopausal breast cancer risk. Arch Intern Med. 2007;167(19):2091-102.

11. Hidayat K, Yang CM, Shi BM. Body fatness at a young age, body fatness gain and risk of breast cancer: systematic review and meta-analysis of cohort studies. Obes Rev: Off J Int Assoc Study Obes. 2018;19(2):254-68. https://doi.org/10.1111/ obr.12627.

12. Bardia A, Vachon CM, Olson JE, et al. Relative weight at age 12 and risk of postmenopausal breast cancer. Cancer Epidemiol Biomark Prev. 2008;17(2):374-8.

13. Key T, Appleby P, Barnes I, Reeves G. Endogenous sex hormones and breast cancer in postmenopausal women: reanalysis of nine prospective studies. J Natl Cancer Inst. 2002;94(8):606-16.

14. Key TJ, Appleby PN, Reeves GK, et al. Body mass index, serum sex hormones, and breast cancer risk in postmenopausal women. J Natl Cancer Inst. 2003;95(16):1218-26.

15. Rinaldi S, Key TJ, Peeters PH, et al. Anthropometric measures, endogenous sex steroids and breast cancer risk in postmenopausal women: a study within the EPIC cohort. Int J Cancer. 2006;118(11):2832-9.

16. Renehan AG, Roberts DL, Dive C. Obesity and cancer: pathophysiological and biological mechanisms. Arch Physiol Biochem. 2008;114(1):71-83.

17. Picon-Ruiz M, Morata-Tarifa C, Valle-Goffin JJ, Friedman ER, Slingerland JM. Obesity and adverse breast cancer risk and outcome: mechanistic insights and strategies for intervention. CA Cancer J Clin. 2017;67(5):378-97. https://doi.org/10.3322/ caac. 21405.

18. Gaudet MM, Gierach GL, Carter BD, et al. Pooled analysis of nine cohorts reveals breast cancer risk factors by tumor molecular subtype. Cancer Res. 2018;78(20):6011-21. https://doi. org/10.1158/0008-5472.CAN-18-0502.

19. Suzuki R, Orsini N, Saji S, Key TJ, Wolk A. Body weight and incidence of breast cancer defined by estrogen and progesterone receptor status - a meta-analysis. Int $\mathrm{J}$ Cancer. 2009;124(3):698-712.

20. Chan DSM, Abar L, Cariolou M, et al. World Cancer Research Fund International: continuous update project-systematic literature review and meta-analysis of observational cohort studies on physical activity, sedentary behavior, adiposity, and weight change and breast cancer risk. Cancer Causes Control. 2019;30(11):1183200. https://doi.org/10.1007/s10552-019-01223-w.

21. Smith-Warner SA, Spiegelman D, Ritz J, et al. Methods for pooling results of epidemiologic studies: the pooling project of prospective studies of diet and cancer. Am J Epidemiol. 2006;163(11):1053-64.

22. Omenn GS, Goodman G, Thornquist M, et al. The beta-carotene and retinol efficacy trial (CARET) for chemoprevention of lung cancer in high risk populations: smokers and asbestos-exposed workers. Cancer Res. 1994;54(7 Suppl):2038s-43s.

23. Dallal CM, Sullivan-Halley J, Ross RK, et al. Long-term recreational physical activity and risk of invasive and in situ breast cancer: the California teachers study. Arch Intern Med. 2007;167(4):408-15.

24. Silvera SA, Jain M, Howe GR, Miller AB, Rohan TE. Energy balance and breast cancer risk: a prospective cohort study. Breast Cancer Res Treat. 2006;97(1):97-106.

25. Calle EE, Rodriguez C, Walker-Thurmond K, Thun MJ. Overweight, obesity, and mortality from cancer in a prospectively studied cohort of U.S. adults. N Engl J Med. 2003;348(17):1625-38.

26. Harvie M, Howell A, Vierkant RA, et al. Association of gain and loss of weight before and after menopause with risk of postmenopausal breast cancer in the Iowa women's health study. Cancer Epidemiol Biomark Prev. 2005;14(3):656-61.

27. Suzuki R, Iwasaki M, Inoue $M$, et al. Body weight at age 20 years, subsequent weight change and breast cancer risk defined by estrogen and progesterone receptor status-the Japan public health center-based prospective study. Int J Cancer. 2011;129(5):1214-24.

28. Krishnan K, Bassett JK, MacInnis RJ, et al. Associations between weight in early adulthood, change in weight, and breast cancer risk in postmenopausal women. Cancer Epidemiol Biomark Prev. 2013;22(8):1409-16. https://doi.org/10.1158/1055-9965. EPI-13-0136.

29. Kolonel LN, Altshuler D, Henderson BE. The multiethnic cohort study: exploring genes, lifestyle and cancer risk. Nat Rev Cancer. 2004;4(7):519-27.

30. van den Brandt PA, Dirx MJ, Ronckers CM, van den Hoogen P, Goldbohm RA. Height, weight change, and postmenopausal breast cancer risk: The Netherlands Cohort Study. Cancer Causes Control. 1997;8(1):39-47.

31. Zeleniuch-Jacquotte A, Gu Y, Shore RE, et al. Postmenopausal levels of sex hormones and risk of breast carcinoma in situ: results of a prospective study. Int J Cancer. 2005;114(2):323-7.

32. Eliassen AH, Colditz GA, Rosner B, Willett WC, Hankinson SE. Adult weight change and risk of postmenopausal breast cancer. JAMA. 2006;296(2):193-201.

33. Agnoli C, Berrino F, Abagnato CA, et al. Metabolic syndrome and postmenopausal breast cancer in the ORDET cohort: a nested case-control study. Nutr Metab Cardiovasc Dis. 2010;20(1):41-8.

34. Prorok PC, Andriole GL, Bresalier RS, et al. Design of the Prostate, Lung, Colorectal and Ovarian (PLCO) cancer screening trial. Control Clin Trials. 2000;21(6 Suppl):273S-309S.

35. Suzuki R, Rylander-Rudqvist T, Ye W, Saji S, Wolk A. Body weight and postmenopausal breast cancer risk defined by estrogen and progesterone receptor status among Swedish women: a prospective cohort study. Int J Cancer. 2006;119(7):1683-9. 
36. Rexrode KM, Lee IM, Cook NR, Hennekens CH, Buring JE. Baseline characteristics of participants in the Women's Health Study. J Womens Health Gend Based Med. 2000;9(1):19-27.

37. Weiderpass E, Braaten T, Magnusson C, et al. A prospective study of body size in different periods of life and risk of premenopausal breast cancer. Cancer Epidemiol Biomark Prev. 2004;13(7):1121-7.

38. Brewster AM, Christo DK, Lai H, Helzlsouer K. Breast carcinoma chemoprevention in the community setting. Estimating risks and benefits. Cancer. 2005;103(6):1147-53. https://doi.org/10.1002/ cncr.20882.

39. Velie EM, Schairer C, Flood A, He JP, Khattree R, Schatzkin A. Empirically derived dietary patterns and risk of postmenopausal breast cancer in a large prospective cohort study. Am J Clin Nutr. 2005;82(6):1308-19. https://doi.org/10.1093/ajcn/82.6.1308.

40. Genkinger JM, Platz EA, Hoffman SC, Comstock GW, Helzlsouer KJ. Fruit, vegetable, and antioxidant intake and all-cause, cancer, and cardiovascular disease mortality in a community-dwelling population in Washington County, Maryland. Am J Epidemiol. 2004;160(12):1223-33. https://doi.org/10.1093/aje/kwh339.

41. Elands RJJ, Offermans NSM, Simons C, et al. Associations of adult-attained height and early life energy restriction with postmenopausal breast cancer risk according to estrogen and progesterone receptor status. Int J Cancer. 2019;144(8):1844-57. https ://doi.org/10.1002/ijc.31890.

42. Lee S, Kolonel L, Wilkens L, Wan P, Henderson B, Pike M. Postmenopausal hormone therapy and breast cancer risk: the Multiethnic Cohort. Int J Cancer. 2006;118(5):1285-91. https://doi. org/10.1002/ijc.21481.

43. Calle EE, Rodriguez C, Jacobs EJ, et al. The American Cancer Society Cancer Prevention Study II Nutrition Cohort: rationale, study design, and baseline characteristics. Cancer. 2002;94(9):2490-501. https://doi.org/10.1002/cncr.101970.

44. Allison KH, Hammond MEH, Dowsett M, et al. Estrogen and progesterone receptor testing in breast cancer: ASCO/CAP guideline update. J Clin Oncol. 2020;38(12):1346-66. https://doi. org/10.1200/JCO.19.02309.

45. Cox DR. Regression models and life-tables. J R Stat Soc B. 1982;34(2):187-220.

46. van den Brandt PA, Goldbohm RA, van 't Veer P, Volovics A, Hermus RJ, Sturmans F. A large-scale prospective cohort study on diet and cancer in The Netherlands. J Clin Epidemiol. 1990;43(3):285-95.

47. Zhang X, Spiegelman D, Baglietto L, et al. Carotenoid intakes and risk of breast cancer defined by estrogen receptor and progesterone receptor status: a pooled analysis of 18 prospective cohort studies. Am J Clin Nutr. 2012;95(3):713-25. https://doi. org/10.3945/ajcn.111.014415.

48. Greenland S. Quantifying biases in causal models: classical confounding vs collider-stratification bias. Epidemiology. 2003;14(3):300-6.

49. Smith-Warner SA, Spiegelman D, Yaun SS, et al. Alcohol and breast cancer in women: a pooled analysis of cohort studies. JAMA. 1998;279(7):535-40.

50. Joffe MM, Rosenbaum PR. Invited commentary: propensity scores. Am J Epidemiol. 1999;150(4):327-33. https://doi. org/10.1093/oxfordjournals.aje.a010011.

51. Cepeda MS, Boston R, Farrar JT, Strom BL. Comparison of logistic regression versus propensity score when the number of events is low and there are multiple confounders. Am J Epidemiol. 2003;158(3):280-7. https://doi.org/10.1093/aje/kwg115.

52. Laird NM, Ware JH. Random-effects models for longitudinal data. Biometrics. 1982;38(4):963-74.

53. DerSimonian R, Laird N. Meta-analysis in clinical trials. Control Clin Trials. 1986;7(3):177-88.
54. Anderson TW. Introduction to multivariate statistics. New York, NY: John Wiley \& Sons; 1984.

55. Durrleman S, Simon R. Flexible regression models with cubic splines. Stat Med. 1989;8(5):551-61.

56. Reeves GK, Beral V, Green J, Gathani T, Bull D, Million Women Study C. Hormonal therapy for menopause and breast-cancer risk by histological type: a cohort study and meta-analysis. Lancet Oncol. 2006;7(11):910-8. https://doi.org/10.1016/s1470 -2045(06)70911-1.

57. Fang X, Wei J, He X, et al. Quantitative association between body mass index and the risk of cancer: a global Meta-analysis of prospective cohort studies. Int J Cancer. 2018;143(7):1595-603. https ://doi.org/10.1002/ijc.31553.

58. Guo W, Key TJ, Reeves GK. Adiposity and breast cancer risk in postmenopausal women: results from the UK Biobank prospective cohort. Int J Cancer. 2018;143(5):1037-46. https://doi. org/10.1002/ijc.31394.

59. Wang $\mathrm{L}, \mathrm{Jin} \mathrm{G}, \mathrm{Yu} \mathrm{C}$, et al. Cancer incidence in relation to body fatness among 0.5 million men and women: findings from the China Kadoorie Biobank. Int J Cancer. 2019. https://doi. org/10.1002/ijc.32394.

60. Lahmann PH, Hoffmann K, Allen N, et al. Body size and breast cancer risk: findings from the European Prospective Investigation into Cancer And Nutrition (EPIC). Int J Cancer. 2004;111(5):76271. https://doi.org/10.1002/ijc.20315.

61. Siiteri PK. Adipose tissue as a source of hormones. Am J Clin Nutr. 1987;45(1 Suppl):277-82. https://doi.org/10.1093/ ajcn/45.1.277.

62. Renehan AG, Zwahlen M, Egger M. Adiposity and cancer risk: new mechanistic insights from epidemiology. Nat Rev Cancer. 2015;15(8):484-98. https://doi.org/10.1038/nrc3967.

63. Song M, Willett WC, Hu FB, et al. Trajectory of body shape across the lifespan and cancer risk. Int J Cancer. 2016;138(10):2383-95. https://doi.org/10.1002/ijc.29981.

64. Suzuki R, Saji S, Toi M. Impact of body mass index on breast cancer in accordance with the life-stage of women. Frontiers in oncology. 2012;2:123. https://doi.org/10.3389/fonc.2012.00123.

65. Sherman BM, Korenman SG. Measurement of serum LH, FSH, estradiol and progesterone in disorders of the human menstrual cycle: the inadequate luteal phase. J Clin Endocrinol Metab. 1974;39(1):145-9. https://doi.org/10.1210/jcem-39-1-145.

66. Stoll BA. Breast cancer: the obesity connection. Br J Cancer. 1994;69(5):799-801. https://doi.org/10.1038/bjc.1994.157.

67. Key TJ, Pike MC. The role of oestrogens and progestagens in the epidemiology and prevention of breast cancer. Eur. J. Cancer Clin. Oncol. 1988;24(1):29-43. https://doi.org/10.1016/02775379(88)90173-3.

68. Michels KB, Terry KL, Willett WC. Longitudinal study on the role of body size in premenopausal breast cancer. Arch Intern Med. 2006;166(21):2395-402.

69. Palmer JR, Adams-Campbell LL, Boggs DA, Wise LA, Rosenberg L. A prospective study of body size and breast cancer in black women. Cancer Epidemiol Biomarkers Prev. 2007;16(9): 1795-802.

70. Oh H, Boeke CE, Tamimi RM, et al. The interaction between early-life body size and physical activity on risk of breast cancer. Int J Cancer. 2015;137(3):571-81. https://doi.org/10.1002/ ijc. 29272.

71. Zhao H, Wang J, Fang D, et al. Adiposity results in metabolic and inflammation differences in premenopausal and postmenopausal women consistent with the difference in breast cancer risk. Horm Cancer. 2018;9(4):229-39. https://doi.org/10.1007/s1267 2-018-0329-6.

72. Hilakivi-Clarke L, Forsen T, Eriksson JG, et al. Tallness and overweight during childhood have opposing effects on breast cancer risk. Br J Cancer. 2001;85(11):1680-4. 
73. Nagasawa H, Yanai R, Shodono M, Nakamura T, Tanabe Y. Effect of neonatally administered estrogen or prolactin on normal and neoplastic mammary growth and serum estradiol-17 beta level in rats. Cancer Res. 1974;34(10):2643-6.

74. Grubbs CJ, Farnell DR, Hill DL, McDonough KC. Chemoprevention of $N$-nitroso- $N$-methylurea-induced mammary cancers by pretreatment with 17 beta-estradiol and progesterone. J Natl Cancer Inst. 1985;74(4):927-31.

75. Poole EM, Tworoger SS, Hankinson SE, Schernhammer ES, Pollak MN, Baer HJ. Body size in early life and adult levels of insulin-like growth factor 1 and insulin-like growth factor binding protein 3. Am J Epidemiol. 2011;174(6):642-51. https://doi. org/10.1093/aje/kwr123.

76. Oh $\mathrm{H}$, Eliassen $\mathrm{AH}, \mathrm{Beck} \mathrm{AH}$, et al. Breast cancer risk factors in relation to estrogen receptor, progesterone receptor, insulin-like growth factor-1 receptor, and Ki67 expression in normal breast tissue. NPJ breast cancer. 2017;3:39. https://doi.org/10.1038/s4152 3-017-0041-7.

77. Rosenfeld RG. Insulin-like growth factors and the basis of growth. N Engl J Med. 2003;349(23):2184-6. https://doi.org/10.1056/ NEJMp038156.

78. Pollak M. The insulin and insulin-like growth factor receptor family in neoplasia: an update. Nat Rev Cancer. 2012;12(3):159-69.
79. Endogenous H, Breast Cancer Collaborative G, Key TJ, Appleby PN, Reeves GK, Roddam AW. Insulin-like growth factor 1 (IGF1), IGF binding protein 3 (IGFBP3), and breast cancer risk: pooled individual data analysis of 17 prospective studies. Lancet Oncol. 2010;11(6):530-42. https://doi.org/10.1016/s1470 -2045(10)70095-4.

80. Murphy N, Knuppel A, Papadimitriou N, et al. Insulin-like growth factor-1, insulin-like growth factor-binding protein-3, and breast cancer risk: observational and Mendelian randomization analyses with approximately 430000 women. Ann Oncol. 2020;31(5):6419. https://doi.org/10.1016/j.annonc.2020.01.066.

81. Collaborative Group on Hormonal Factors in Breast Cancer. Type and timing of menopausal hormone therapy and breast cancer risk: individual participant meta-analysis of the worldwide epidemiological evidence. Lancet. 2019;394(10204):1159-68. https ://doi.org/10.1016/S0140-6736(19)31709-X.

82. Sprague BL, Gangnon RE, Hampton JM, et al. Variation in breast cancer-risk factor associations by method of detection: results from a series of case-control studies. Am J Epidemiol. 2015;181(12):956-69. https://doi.org/10.1093/aje/kwu474.

Publisher's Note Springer Nature remains neutral with regard to jurisdictional claims in published maps and institutional affiliations.

\section{Affiliations}

Piet A. van den Brandt ${ }^{1,2}$ (]) Regina G. Ziegler ${ }^{3} \cdot$ Molin Wang ${ }^{4,5,6} \cdot$ Tao Hou $^{7} \cdot{\text { Ruifeng } \mathrm{Li}^{7} \cdot \text { Hans-Olov Adami }}^{8,9}$. Claudia Agnoli ${ }^{10}$. Leslie Bernstein ${ }^{11}$. Julie E. Buring ${ }^{4,12} \cdot$ Yu Chen $^{13}$. Avonne E. Connor ${ }^{14}$. A. Heather Eliassen ${ }^{4,6}$. Jeanine M. Genkinger ${ }^{15,16}$. Gretchen Gierach ${ }^{3}$. Graham G. Giles ${ }^{17,18,19}$. Gary G. Goodman ${ }^{20}$. Niclas Håkansson ${ }^{21}$. Vittorio $\mathrm{Krogh}^{10}$. Loic Le Marchand ${ }^{22} \cdot$ I-Min Lee ${ }^{4,12} \cdot$ Linda M. Liao $^{3}$ - M. Elena Martinez ${ }^{23,24}$. Anthony B. Miller ${ }^{25}$. Roger L. Milne ${ }^{17,18,19} \cdot$ Marian L. Neuhouser ${ }^{20}$ - Alpa V. Patel ${ }^{26}$. Anna Prizment ${ }^{27,28} \cdot$ Kim Robien $^{29}$. Thomas E. Rohan ${ }^{30}$ - Norie Sawada ${ }^{31}$ - Leo J. Schouten ${ }^{1} \cdot$ Rashmi Sinha $^{3} \cdot$ Rachael Z. Stolzenberg-Solomon $^{3}$. Lauren R. Teras ${ }^{26}$. Shoichiro Tsugane ${ }^{31}$. Kala Visvanathan ${ }^{14}$. Elisabete Weiderpass ${ }^{32} \cdot$ Kami K. White $^{22}$. Walter C. Willett ${ }^{4,6,7}$. Alicja Wolk ${ }^{21,33}$. Anne Zeleniuch-Jacquotte ${ }^{13}$. Stephanie A. Smith-Warner ${ }^{4,7}$

Piet A. van den Brandt

PA.vandenBrandt@maastrichtuniversity.nl

1 Department of Epidemiology, GROW - School for Oncology and Developmental Biology, Maastricht University, PO Box 616, 6200 MD Maastricht, The Netherlands

2 Department of Epidemiology, Care and Public Health Institute (CAPHRI), Maastricht University, PO Box 616, 6200 MD Maastricht, The Netherlands

3 Division of Cancer Epidemiology and Genetics, National Cancer Institute, National Institutes of Health, Bethesda, MD, USA

4 Department of Epidemiology, Harvard T.H. Chan School of Public Health, Boston, MA, USA

5 Department of Biostatistics, Harvard T.H. Chan School of Public Health, Boston, MA, USA

6 Channing Division of Network Medicine, Department of Medicine, Harvard Medical School, Boston, MA, USA

7 Department of Nutrition, Harvard T.H Chan School of Public Health, Boston, MA, USA
8 Department of Medical Epidemiology and Biostatistics, Karolinska Institutet, Stockholm, Sweden

9 Clinical Effectiveness Group, Institute of Health, University of Oslo, Oslo, Norway

10 Epidemiology and Prevention Unit, Department of Research, Fondazione Istituto Nazionale Tumori, 20133 Milan, Italy

11 Department of Population Sciences, Beckman Research Institute, City of Hope, Duarte, CA, USA

12 Division of Preventive Medicine, Brigham and Women's Hospital, Harvard Medical School, Boston, MA, USA

13 Division of Epidemiology, Department of Population Health and Department of Environmental Medicine, New York University School of Medicine, New York, USA

14 Department of Epidemiology, Johns Hopkins Bloomberg School of Public Health, Baltimore, MD, USA

15 Department of Epidemiology, Columbia University Mailman School of Public Health, New York, NY, USA

16 Herbert Irving Comprehensive Cancer Center, Columbia University Irving Medical Center, New York, NY, USA 
17 Cancer Epidemiology Division, Cancer Council Victoria, Melbourne, VIC, Australia

18 Centre for Epidemiology and Biostatistics, Melbourne School of Population and Global Health, The University of Melbourne, Melbourne, VIC, Australia

19 Precision Medicine, School of Clinical Sciences at Monash Health, Monash University, Clayton, VIC, Australia

20 Division of Public Health Sciences, Fred Hutchinson Cancer Research Center, Seattle, WA, USA

21 Unit of Cardiovascular and Nutritional Epidemiology, Institute of Environmental Medicine, Karolinska Institutet, Stockholm, Sweden

22 Cancer Epidemiology Program, University of Hawaii Cancer Center, Honolulu, HI, USA

23 Department of Family Medicine and Public Health School of Medicine, University of California San Diego, La Jolla, CA, USA

24 Moores Cancer Center, University of California San Diego, La Jolla, CA, USA

25 Dalla Lana School of Public Health, University of Toronto, Toronto, ON, Canada
26 Epidemiology Research Program, American Cancer Society, Atlanta, GA, USA

27 Division of Hematology, Oncology and Transplantation, University of Minnesota Medical School, Minneapolis, MN, USA

28 Division of Epidemiology and Community Health, School of Public Health, University of Minnesota, Minneapolis, MN, USA

29 Department of Exercise and Nutrition Sciences, Milken Institute School of Public Health, George Washington University, Washington, DC, USA

30 Department of Epidemiology and Population Health, Albert Einstein College of Medicine, Bronx, USA

31 Epidemiology and Prevention Group, Research Center for Cancer Prevention and Screening, National Cancer Center, Tokyo, Japan

32 International Agency for Research on Cancer, World Health Organization, Lyon, France

33 Department of Surgical Sciences, Uppsala University, Uppsala, Sweden 